This item was submitted to Loughborough's Research Repository by the author.

Items in Figshare are protected by copyright, with all rights reserved, unless otherwise indicated.

\title{
Why do product-market strategies fail? A sociostructural examination under conditions of adherence
}

PLEASE CITE THE PUBLISHED VERSION

https://doi.org/10.1177/1059601110383408

PUBLISHER

SAGE (@ the authors)

VERSION

AM (Accepted Manuscript)

\section{PUBLISHER STATEMENT}

This work is made available according to the conditions of the Creative Commons Attribution-NonCommercialNoDerivatives 4.0 International (CC BY-NC-ND 4.0) licence. Full details of this licence are available at: https://creativecommons.org/licenses/by-nc-nd/4.0/

\section{LICENCE}

CC BY-NC-ND 4.0

\section{REPOSITORY RECORD}

Hughes, Paul, Mathew Hughes, and Robert E. Morgan. 2019. "Why Do Product-market Strategies Fail? A Sociostructural Examination Under Conditions of Adherence”. figshare. https://hdl.handle.net/2134/26373. 


\title{
Why Do Product-Market Strategies Fail? A Socio-Structural Examination under Conditions of Adherence
}

\author{
Paul Hughes \\ Loughborough University \\ Mathew Hughes ${ }^{\dagger}$ \\ University of Nottingham \\ Robert E. Morgan \\ Cardiff University
}

Forthcoming in Group and Organization Management

Dr. Paul Hughes, Loughborough University, Business School, Loughborough, Leicestershire LE11 3TU, United Kingdom. Tel: +44 1509 228274. Fax: +44 1509 223962. E-mail:

p.hughes@lboro.ac.uk. Dr. Mathew Hughes (corresponding author) ${ }^{\dagger}$, University of Nottingham, Nottingham, University Business School, Jubilee Campus, Wollaton Road, Nottingham NG8 1BB, United Kingdom. Tel: +44 115 8467747. E-mail: mat.hughes@nottingham.ac.uk. Prof. Robert E. Morgan, Cardiff University, Cardiff Business School, Colum Drive, Cardiff CF10 3EU, United Kingdom. Tel: +44 292087 0001. Fax: +44 292087 4419. E-

mail: morganre@cardiff.ac.uk. 


\title{
Why Do Product-Market Strategies Fail?
}

\section{A Socio-Structural Examination under Conditions of Adherence}

\begin{abstract}
We contend that structural and managerial antecedents of strategy failure exist and the extent to which these determine failure is different under conditions of high and low adherence to strategy. Our results support these arguments and demonstrate that the drivers of failure differ according to the unusual strategy process environment of both types of firms. Resource scarcity is found to be a common antecedent to strategy failure in organizations regardless of adherence. From there, managerial conditions (symbolic information use, strategy championing, and tenure) drive strategy failure in high adherence firms. But only structural conditions (formalization and resource scarcity) are antecedents of strategy failure in low adherence firms, while failure is mitigated by centralized decision-making.
\end{abstract}

Key-words: Strategy failure; adherence; championing; product-market strategies;

\section{Funding}

This research received no specific grant from any funding agency in the public, commercial, or not-for-profit sectors. 


\section{Introduction \& Background}

The strategic management literature is replete with studies offering models of high performance and avenues to success, yet despite recent treatises, research is relatively silent on the causes of failure (e.g., Finkelstein, 2003; Mellahi and Wilkinson, 2004; Mellahi, 2005; Sheppard and Chowdhury, 2005). Scholars have made attempts to consider new product/project failures (Royer, 2003; Biyalogorsky, Boulding, and Staelin, 2006) and organizational failure (Mellahi and Wilkinson, 2004; Mellahi, 2005; Sheppard and Chowdhury, 2005) but have rarely attempted to address the issue of strategy failure (e.g., Baumard and Starbuck, 2005). We define strategy failure as considerably substandard business performance relative to major, direct competitor referents. In other words, the strategy is not meeting the firm's performance objectives and performance is far worse relative to competitors, and is thus a failing strategy. This view of strategy failure is consistent with other works in this domain (Baumard and Starbuck, 2005) and accepts that strategy failure does not necessarily mean the death of a company, but can be a critical factor in this happening (Finkelstein, 2003). The literature on organizational failure views this as the death of the organization (Hambrick and D'Aveni, 1988, 1992; D’Aveni, 1989; Finkelstein, 2003; Mellahi and Wilkinson, 2004; Mellahi, 2005; Wilkinson and Mellahi, 2005) and many potential causes of organizational failure arise in the literature and include crisis (Schendel, Patton, and Riggs, 1976); strategic extremism (Hambrick and D’Aveni, 1988); resource deteriorations (D’Aveni, 1989); information processing deficiencies (Hambrick and D’Aveni, 1992; Finkelstein, 2003); management team composition (Mellahi, 2005); and learning deficiencies (Cannon and Edmondson, 2005). The accepted view in the failure literature is that organizational death is not instantaneous but rather occurs as a downward spiral or over time through stages before death occurs (Hambrick and D’Aveni, 1988, 1992; Finkelstein, 2003; 
Sheppard and Chowdhury, 2005). We suggest that strategy failure does not necessarily mean the death of the company because strategy failure can be addressed and, ipso facto, would provide an opportunity for strategic change and turnaround. If strategy failure is not addressed then strategic paralysis could take hold and lead to organizational death by strategy failure (Whetten, 1980). In isolation then, strategy failure can be a cause in itself of organizational failure but strategy failure may not necessarily lead inevitably to absolute organizational failure. As Finkelstein (2003) noted, stupidity or dishonesty rarely causes organizational failure, but rather, multiple strategy failures and a failure to address the underlying problems that exist are the ultimate reasons for death occurring.

Examining factors involved in strategy failure is particularly difficult as circumstances that can lead towards success can lead to failure depending on context. Comprehensive planning, for example, can lead to higher performance (Powell, 1992) but in turbulent times can become a hindrance that causes inflexibility that reduces performance and lead to failure (Atuahene-Gima and Murray, 2004). Indeed, learning from repeated successes can make future strategy failures more likely (Baumard and Starbuck, 2005). As Mellahi and Wilkinson (2004: 34) indicated, any attempt to explain failure "will not be complete unless the interplay between contextual forces and organizational dynamics is taken into account”. Understanding how failure happens then requires consideration of the context in which it can occur. As yet however, such research is critically lacking in the strategy literature.

Employing adherence theory we consider the context of strategy adherence, or persistence with current strategy, which is the antithesis to strategic fit theory. Strategic managers must understand their market environment, customer needs, value drivers, and competitors' behavior and from this, formulate and implement the correct product-market strategy (Varadarajan and Jayachandran, 1999). Consequently, strategic managers invest much time and effort in this 
strategy-making process to bring the product-market strategy to fruition (Menon, Bharadwaj, Adidam, and Edison, 1999). A key decision facing strategic managers is whether to persist or adhere with the current product-market strategy, or, change the direction of the organization and follow a new strategy (Lant, Milliken, and Batra, 1992). Indeed, Menon et al. (1999: 21) identified from interviews with managers that "staying the course" is an important aspect of successful strategy-making. This decision would appear, on the face of it, to be a relatively simple one to address: if the environment changes substantively enough then surely a new product-market strategy is best? After all, the organization will not be in 'fit' with its market environment and so requires a new strategy (Sheppard and Chowdhury, 2005) as advocated in strategic fit theory. In following traditional fit theory, firms would therefore always adapt strategy to fit their external environment and internal circumstances so that the most appropriate strategy is followed. This however is a misconception. Fox-Wolfgramm, Boal, and Hunt (1998) discovered that strategic changes are in fact uncharacteristic of firms even in the face of major environmental upheaval. Rather, firms will simply look to make minor first-order modifications to the product-market strategy rather than make more substantial strategic changes that radically alter strategy and strategic direction. These minor first-order changes in reality have no bearing on the current strategy or the strategic direction of the firm. Indeed, managers tend to react more positively to changes that would only modify strategy incrementally (Baumard and Starbuck, 2005). Ultimately, the organizational conditions associated with high or low adherence firms may be similar, but, the effect of these contextual conditions on leading to success or failure can differ (e.g., Hughes and Morgan, 2007).

Our research goal is to address the question of how strategy failure occurs in organizations that are predisposed toward changing or persisting with current strategy. In addressing this we make several contributions. First, we identify managerial and structural 
drivers of strategy failure and examine these in respect to high and low levels of adherence through multi-group structural equation modeling. In doing so, we contribute knowledge of critical antecedents of strategy failure that function under different firm conditions. As a preview, we reveal that high adherence organizations are most affected by managerial factors whilst low adherence organizations are primarily affected by structural elements. Thus, we dispel the belief that a common set of conditions drive failure in each type of firm. Second, we dispel the normative assumption that championing is invariably beneficial for organizations. Consequently, we contribute to that literature by confirming Royer's (2003) contentions that championing can have negative implications for organizations by inducing inertia to move away from the championed strategy even when strategy is failing. Third, we demonstrate that low adherence firms, those more open to adaptation and change, may also suffer strategy failure from increased formalization and resource scarcity but this failure can be mitigated by increased centralized control. As such, we break up the adherence dynamic presented in the literature so far to demonstrate that low adherence in and of itself does not avert the risk of failure. These three contributions offer important managerial and theory-based implications which we discuss to close this work.

\section{Hypothesis Development}

'Adherence' has been described as 'realizing' the product-market strategy (Covin, Slevin, and Schultz, 1997) based on the belief that making constant changes to strategy 'inhibits' the actual adoption of the chosen strategy (Hughes and Morgan, 2007). We describe adherence as persistence with current strategy (Lant et al., 1992). Minor modifications to product-market strategy may be made over time but, as the adherence literature stresses, these adjustments are not 
second-order strategic changes but are first-order modifications made over time, which do not result in changes in the prevailing strategic direction (Fox-Wolfgramm et al., 1998).

Adhering to the product-market strategy demonstrates confidence in that strategy and can lead to efficiency gains (Lant et al., 1992), more effective deployment of strategic resources (Hughes and Morgan, 2007), generate performance benefits (Covin et al., 1997; Hughes and Morgan, 2007), and may have learning benefits for strategic managers insomuch that they can benefit from understanding more about the product-market strategy and its effects on markets and customers (Hughes and Morgan, 2007). Conversely, scholars also advocate flexibility in productmarket strategies as a means to enhance performance and competitive advantage (e.g., Grewal and Tansuhaj, 2001). Adhering to strategy in the face of changing market environments and customer demands can erode strategic fit and competitive advantage, therefore rendering the strategy inappropriate as it is not aligned with the market and customer demands. Consequently, strategic managers face a strategic paradox. On the one hand, strategy adherence can have notional benefits; on the other hand, it can lead to situations where failure can arise as it prevents deviance from current course of action. To capture this paradoxical situation, we examine two groups of organizations: the first group of firms is predisposed to adhere to current strategy and the second group of firms is predisposed to adhere less and is readily willing to adapt strategy.

Our interest lies in the internal characteristics of these groups of organizations and in particular what conditions might drive strategy failure at different levels of adherence. In doing so, we overcome the assumption prevalent in adherence theory that such firms with high or low adherence share simply high or low levels of the same structural and managerial characteristics. It is apparent from adherence theory that internal circumstances are critical to the view of whether to adhere (high adherence) or change strategy (low adherence) (e.g., Fox-Wolfgramm et al., 1998). Consequently, and given the suggestion of Mellahi and Wilkinson (2004) to focus on 
organizational dynamics, it is prudent to advance this research into strategy failure by examining internal characteristics that can theoretically lead to strategy failure but are as yet unfounded empirically due to the lack of substantive research into strategy failure. We distinguish between 'structural characteristics' and 'managerial characteristics' as drivers of strategy failure (Figure 1). We suspect that high adherence firms will differ characteristically from low adherence firms as the internal conditions for such behavior to occur are likely to be different. For instance, low adherence implies the ability to be flexible and adaptive which is unlikely to be possible in highly formalized firms. However, high formalization of processes and procedures is likely to be useful for high adherence firms to stay the course and ensure the desired strategy is employed and not deviated from.

\section{Insert Figure 1 here}

\section{Structural Characteristics}

We consider centralization, formalization, and resource scarcity as structural characteristics of organizations that can be influential in creating conditions for failure (e.g., Finkelstein, 2003). Together, these conditions can act against flexibility to change strategy despite being within the realm of management control (Covin et al., 1997; Finkelstein, 2003). Centralization relates to the concentration of decision-making authority at the highest levels of the firm, whilst formalization is the degree to which standardized rules and procedures dictate how strategic activities are to be performed (e.g., Vorhies and Morgan, 2003). Excessive centralization and formalization is associated with bureaucracy and mechanistic processes that can serve to slow down strategic decision-making, lower cross-functional integration, lower consensus in strategy-making, and compromise effective market information processing (Slevin and Covin, 1997; Menon et al., 1999). Consequently, it is likely that these factors can lead to strategy failure. Indeed, excessive control brought about by autocratic management, centralization, and formalization were direct 
causes in the failure of Wang Labs (Finkelstein, 2003). We suspect that the effect of centralization and formalization as structural variables will be stronger in low adherence firms however. Low adherence firms rely on flexibility and a capacity for adaptiveness. To do so successfully appears dependent on the structural conditions of the firm inasmuch as that adaptability would likely be constrained under conditions of high centralization and formalization. Organic structures characterized by decentralization and informalized rules and procedures tend to promote greater flexibility whilst inflexibility is true of the opposite (e.g., Slevin and Covin, 1997). Inflexibility is of less a concern in high adherence firms as strategy remains relatively consistent and unchanged over time. It would also be expected that high adherence firms may characteristically be centralized and formalized in order to maintain control and consistency over strategic direction and coordinate the activities of, what are often, complex organizations (e.g., Sull, 1999). As such, these conditions may not be prevalent in failure but are likely to be issues of concern in low adherence firms. Thus:

Hypothesis 1. Centralization is negatively related to strategy failure in (a) high adherence firms but is positively related to strategy failure in (b) low adherence firms.

Hypothesis 2. Formalization is negatively related to strategy failure in (a) high adherence firms but is positively related to strategy failure in (b) low adherence firms.

D'Aveni (1989) proposed that resources deteriorations are important causes of decline. Firms with unavailable resources at the time of the implementation effort would be more constrained in their ability to initiate appropriate actions (Hambrick and D'Aveni, 1988). The presence of slack resources, such as cash, stock, or access to credit can provide a firm with the cushion necessary to implement a strategy (Barker and Duhaime, 1997) and their absence could lead to adherence with disregard for strategic fit (Covin et al., 1997). Slack resources help firms absorb the effects of performance downturns and provide a basis to take effective actions. As 
such, resources are likely a key issue in strategy failure as the resource-base can change over time after strategy has been implemented and then undermine the effectiveness of the strategy, thereby leading to failure.

Covin et al. (1997) posited that resource scarcity hinders strategic change and can cause adherence. A lack of resources is likely to stifle change and adaptation to changing market environments and customer demands and as a result, competitive advantages and performance will likely erode, perpetuating strategy failure. Whilst it is apparent that resource weaknesses would be potentially disastrous in many firms (West and DeCastro, 2001), we suspect the effect will be worse in high adherence firms. Resource scarcity in high adherence firms can generate myopia to current resources only as sources of strategic options. In effect, change is seen as a threat to this already weak resource base and as threats to the firm's current position and current strategy. The result is defensive action to adhere to current paths as opposed to a fundamental rethink of how change can rejuvenate the organization. Organizations that are flexible ought to be more aware of customers and bases for value creation as part of their predisposition to tolerate uncertainty and accept variability as a part of the strategy process (e.g., Grewal and Tansuhaj, 2001). Accordingly, low adherence firms seek to respond relatively quickly even when resources are limited. However, we propose that whilst low adherence firms are inherently more flexible, a capacity to be flexible requires slack resources (Grewal and Tansuhaj, 2001) and scarcity would undermine this and likely perpetuate strategy failure.

High adherence organizations tend to be more 'stuck in their strategy' and in times of significant market changes, would require plentiful resources to change. Low adherence firms are capable of adapting but resource limitations would still hamper attempts to pursue new strategy avenues when change undermines the current course of action. Thus: 
Hypothesis 3. Resource scarcity is positively related to strategy failure in (a) high

adherence firms and in (b) low adherence firms.

\section{Managerial Characteristics}

We examine symbolic information use, strategy championing, and tenure as managerial characteristics since research has associated these conditions with the perpetuation of historical strategy. Symbolic information use concerns information 'misuse' and Finkelstein (2003) stressed that situations where information is not relayed accurately or is deliberately misused can become significant causes of failure. Symbolic information use is the collection and use of information to justify instinct or previously taken decisions; and the distortion and manipulation of information to support, legitimize, and sustain the opinion or dispositions of a strategic decision-maker (Diamantopoulos and Souchon, 1999; Menon and Varadarajan, 1992; Vyas and Souchon, 2003). Biyalogorsky et al. (2006) found that escalating commitment to failing new products was caused by improper use of initial positive beliefs in the face of new negative information, a situation akin to symbolic information use. Symbolic use should lead to strategy failure as information misuse or manipulation can misleadingly deliver a strong strategic solution which ultimately is not appropriate to the product-market circumstances of the firm. This effect is likely to be stronger in high adherence firms that seek to hold fast to current plans and so lack the flexibility to subsequently move away from their inappropriate strategy. Symbolic information use can lead to the pushing of specific political agendas (Diamantopoulos and Souchon, 1999; Vyas and Souchon, 2003) which may involve pressure to maintain strategic direction when the decision to do so is wrong. Whilst this clearly could be opposite, such as an agenda to push through change, the effect on the firm is likely to be less stressful on performance as change is often required to happen if strategic fit is to be maintained (due to its dynamic nature) (Zajac, Kraatz, and Bresser, 2000). 
Low adherence firms are capable of moving quickly and adapting to environmental circumstances as they arise given their riskier nature and predisposition toward change (Covin et al., 1997). However, this also raises the possibility of symbolic information use pushing the organization toward inappropriate strategic directions or actions. It is easier for political influences or specific agendas to take hold when the organization is not rigid in its approach to strategy and is open to rapid changes in actions (e.g., Diamantopoulos and Souchon, 1999; Vyas and Souchon, 2003). Accordingly, we suspect that information misuse in this manner would also exacerbate the likelihood of failure in low adherence firms. Thus, we submit:

Hypothesis 4. Symbolic information use is positively related to strategy failure in (a) high adherence firms and in (b) low adherence firms.

Championing has been shown in the new product literature to have several positive benefits relating to team performance, new product development, and success (e.g., Howell and Shea, 2001, 2006). However Royer (2003), through case study analysis, associated championing with adherence and the subsequent failure of companies on the basis that too much championing leads to situations where companies repel attempts to abandon failing projects or change strategies when change is a necessity. Because empirical evidence supporting this evidence is scarce however, this association has to be determined quantitatively. We hypothesize that strategy championing can set in motion a risk of strategy failure, in particular in less open and flexible organizations. Excessive championing will trap strategic managers into persisting during times of strategy failure and this will be amplified in high adherence situations as champions push and promote persistence with the current strategy agenda. As agents of strategic managers, champions can mobilize support for the initial strategy but in doing so become vectors for its persistence in spite of change in environmental conditions, effectively binding firms to the strategic status quo (Hambrick, Geletkanycz, and Fredrickson, 1993). Champions then are likely 
to face psychological and peer-related costs in high adherence firms should they suddenly shift course to promote change when strategic managers maintain an adherence perspective. In low adherence firms, deviant behavior by champions to advocate change is more likely to be accepted by employees and strategic managers. Low adherence firms pursue the notion of strategic fit and understand the necessity to change strategy in the face of environmental upheaval. As such, we do not expect championing to lead to an increased risk of failure in this context. Thus:

Hypothesis 5. Strategy championing is positively related to strategy failure in (a) high adherence firms but is negatively related to strategy failure in (b) low adherence firms.

Long, or 'high', tenure is also likely to lead to failure as high tenured strategic managers may be too willing to look to past product-market strategies and practices for actions to employ in today’s markets (c.f. Hambrick et al., 1993). Hambrick and Fukutomi (1991) theorized that the longer the length of time top managers are in their post, the more susceptible they become to limited and symbolic information use, manipulation of their power base, and rely on past strategy decisions to inform future actions. The result is a strategic manager who is unwilling to deviate from their historic decisions. It is on this basis that Hambrick and Fukutomi (1991) put forward their 'dysfunction' thesis. Studies support the validity of this thesis. For example, Miller (1991) and Miller and Shamsie (2001) found that tenure causes dysfunction at around 8-10 years of tenure and firm performance declines in turn. The decline occurs because managers' experiences and successes in post over time shape views of the world that are constrained around their preconceptions and past successful strategies. These conditions lead high-tenured managers to shape organization initiatives increasingly around their own biases (Mellahi and Wilkinson, 2004). Their power base also becomes stronger as tenure increases, which risks problems of adherence (Hambrick and Fukutomi, 1991). Recent studies go further to suggest that performance 
may decline in as little as 24 months of tenure depending on the degree of industry dynamism (Henderson, Miller, and Hambrick, 2006).

With respect to adherence, Finkelstein and Hambrick (1990) demonstrated that longer tenured managers tend toward strategic persistence and a tendency then to resist changing strategy to maintain fit. In effect, tenure exacerbates a tendency to adhere to strategy and to act in narrowly conceived ways when adhering to strategy, irrespective of the performance of that strategy at that moment in time. Accordingly, strategies designed by such managers are likely to become increasingly inappropriate for dealing with today’s contemporary customers, competitors, and dynamic market environments; thereby becoming a cause of failure.

The effect of tenure might be different in low adherence firms, however. In such firms, managers operate and perpetuate conditions of flexibility and change, which encourages oversight, reflection, and revision of firm strategy. Hambrick and Fukutomi (1991) suggested that such conditions will counteract the expected disadvantages of tenure. Thus:

Hypothesis 6. Tenure is positively related to strategy failure in (a) high adherence firms but is negatively related to strategy failure in (b) low adherence firms.

\section{Research Method}

Data were generated from a mail survey of medium-large organizations classified as high technology, industrial manufacturers. Firms were sampled at the strategic business unit level as product-market strategies are business-level strategies. A minimum threshold of 100 full-time employees was set to control for economies of scale and liability of smallness issues and due to their limited capacity for strategic analysis, tendency to rely on informal strategic design, and preoccupation with operational decision-making (e.g., Morgan and Strong, 2003). Firms operating for more than five years were sampled as younger firms can suffer from liabilities of 
newness, which can put survival at risk and can lead to premature failure (Stinchombe, 1965; Sapienza, Autio, George, and Zahra, 2006).

We sampled high technology firms owing to the fact they face environmental turbulence and market change more regularly than traditional firms in stable markets and therefore the issues of strategy failure, fit, and adherence are particularly relevant. Turbulent and hostile environments are unforgiving (Covin et al., 1997) and present two opposing but equally sensible positions for managers to take. Firstly, they could leave little to chance and carefully plan and adhere to their strategies to avoid being caught off guard and provide stability to the firm in unstable climates (Covin et al., 1997). Conversely, the need for strategic flexibility to deal with hostile environments suggests a need to not adhere to strategy so that the firm can best tackle its environmental situation and remain in strategic fit (e.g., Zajac et al., 2000). In benign conditions there may not be a need to deviate from strategies and the likelihood of failure in general should be, prima facie, lower and thus provide a poor context to study strategy failure. Following a systematic random sampling procedure using the Kompass Register, 1000 firms were sampled, each satisfying our high technology criteria.

Preliminary interviews revealed that the most appropriate key informant in a position to have most knowledge regarding the product-market strategy and that could provide the most reliable information regarding the variables contained in the questionnaire was the Head of Marketing. This decision-maker was believed to have most: knowledge of the product-market strategy employed by the firm; insight into the creation of this strategy; and, would have greatest understanding of performance. The mean working experience of the respondents is 22 years and their mean tenure within their current organization is 10 years. This suggests that the respondents will have gained sufficient experience and knowledge of their positions and of product-market strategy. Further, informants are likely to be familiar and experienced with the strategic priorities 
and routines of their respective organizations and thus, be similarly familiar with the strategic decision-making processes in their organizations. Analysis of respondents' belief regarding their level of knowledge relating to the questions contained in the questionnaire was on average 5.62 $($ S.D. $=1.014)$ and their confidence in the extent to which their responses accurately reflected the 'realities’ of involvement in product-market strategy decision-making was again on average 5.62 (S.D. $=.901)$. Overall, we can be confident that the key informant chosen was appropriate.

Survey administration consisted of pre-notification; mailing of a full questionnaire pack; first reminder letter; and, second reminder consisting of a full questionnaire pack. Recommended practice regarding cover letter, questionnaire salience and length, follow-ups, return postage, anonymity, lack of explicit deadlines, and university sponsorship were also applied to encourage the response rate. A total of 139 usable responses were obtained. Respondent analysis revealed the majority to be Heads of Marketing (50.35\%). The remaining respondents were Specialist Directors (24.48\%), Specialist Managers (16.78\%), Senior Marketing Personnel (5.59\%), or other executive personnel appointed at the strategic apex of the firm (2.8\%). Respondent organizations had on average US\$144 million sales turnover in the last 12 month period (standard deviation $[S D]=$ US\$410 million) and the average number of employees equaled $1215(\mathrm{SD}=6280)$. These figures are entirely consistent with past research that examined SBUs of medium-large size. For instance, average firm size in terms of number of employees in the work of Barker and Duhaime (1997) was $1787(\mathrm{SD}=3276)$.

Non-response bias was examined using a variety of methods. First, the Armstrong and Overton (1977) extrapolation method of statistical comparison between groups of early and late respondents revealed no significant differences, at conventional levels, between the variables of interest in the study. Second, we contacted a random sample of 150 non-respondents after all mailings were complete and invited them to participate in the study or ascertain reasons for non- 
response. Of these, 13 companies chose to respond. Analysis of variance between those that did respond and those companies that initially were non-respondents found no significant statistical difference between these groups on all of the constructs in the model. Third, as we had access to objective data on our sampled companies we performed a respondent-non-respondent comparison on a random sample of fifty respondents and fifty non-respondents from our original sample. This examination of non-response bias was performed following the prescriptions of Morgan, Vorhies, and Mason (2009). We examined for significant differences between these companies on firm size, age and net profit. No significant differences were found between respondents and non-respondents.

A number of steps were taken to eliminate the potential for common method bias arising from our single-respondent, self-report approach. We sought to minimize common method bias in developing the questionnaire by relying on objective data for firm size; placing the measurement scales in random order; implied no idealized response; shortened questionnaire length; and provided detailed instructions for its completion. We examined common method bias using the Harman one-factor test (Podsakoff, MacKenzie, Lee, Podsakoff, 2003). All variables were specified in a single factor confirmatory factor analysis: $\chi^{2}$ (d.f.) $=1492.05(252) ; \chi^{2} /$ d.f. $=$ 5.92; root mean square error of approximation $(\mathrm{RMSEA})=.19$; conditional fit index $(\mathrm{CFI})=.59$; incremental fit index $($ IFI $)=.59$; non-normed fit index $(\mathrm{NNFI})=.55$. The $\chi^{2} / \mathrm{d}$.f ratio exceeds the $\leq 2.00$ cutoff (Bollen, 1989); the RMSEA exceeds the .08 level of acceptability (Hu and Bentler, 1999); and the fit indices are far below any accepted threshold. The model fit statistics show significant problems with the single factor solution and so demand its rejection (Hu and Bentler, 1999). Common method bias does not appear to be a threat in our data. 
All scales were drawn from measurement batteries used in previous studies. Symbolic information use was measured using items created by Diamantopoulos and Souchon (1999). Strategy championing and commitment were measured by employing items used by Noble and Mokwa (1999). Centralization and formalization were assessed through measures used by Vorhies and Morgan (2003). Resource scarcity was captured by utilizing reverse-coded resource commitment measures used by Menon et al. (1999). Tenure was assessed by asking the respondent to identify their length of tenure with their current organization. Adherence was assessed through measures developed by Covin et al. (1997). Conventional subjective measures were used to gauge performance over the past year, relative to major, direct competitor referents in meeting specific strategic goals on sales growth, return on investment, profitability, and overall firm performance. These items were reverse-coded to form strategy failure. This approach is consistent with the definition of strategy failure put forth earlier and reflects the difficulties in surveying firms specifically on strategy failure. For measure validation, all multi-item scales were entered simultaneously into a confirmatory factor analysis using the covariance matrix and the maximum likelihood estimation procedure (Table 1). The measurement model fit indexes indicate acceptable fit $\left(\chi^{2}\right.$ [d.f.] $=292.47$ [225]; RMSEA $=.05 ;$ CFI $=.97 ;$ IFI $=.97 ;$ NNFI $=$ .96). All composite reliabilities and average variances extracted were acceptable and within minimum thresholds (Table 2).

Insert Table 1 here

Insert Table 2 here

Results

Multi-group structural equation modeling (SEM) was employed to test the hypotheses using LISREL 8.54. We split the sample by the degree of adherence to form two groups, the first 
consisting of high adherence firms ( $\mathrm{n}=93$ ) and the second consisting of low adherence firms (n = 46). Two structural models were specified. The first model was a restricted model in which the $\gamma$ parameters linking the structural and managerial characteristics to strategy failure for the low adherence group were fixed at zero, and the $\gamma$ parameters for the high adherence group were freely estimated. The second model was an unrestricted model in which those $\gamma$ parameters originally fixed at zero were freed. For the restricted model, the fit statistics were $\chi^{2}$ (d.f.) $=$ 511.26 (360); RMSEA $=.08 ; \mathrm{CFI}=.90 ; \mathrm{IFI}=.90 ; \mathrm{NNFI}=.89$. For the unrestricted model, the fit statistics were $\chi^{2}$ (d.f.) $=487.84(354)$; RMSEA $=.07$; CFI $=.90$; IFI $=.90$; NNFI $=.89$. Moving from the restricted model to the unrestricted model resulted in a decrease in $\chi^{2}$ of 23.42 , with an associated decrease of 6 degrees of freedom. This change in $\chi^{2}$ is an improvement in fit significant at $p \leq .01$. This data indicates that the unrestricted model is superior and it is therefore most appropriate to use the results of the unrestricted model in hypothesis testing. The squared multiple correlations for reduced form for failure show that $56 \%$ of variance in failure is explained by the explanatory variables in the model (Jöreskog and Sörbom, 1996). The SEM results for the high and low adherence groups are displayed in Table 3.

\section{Insert Table 3 here}

The results show marked differences between the two groups. For the high adherence group, centralization (H1a) and formalization (H2a) do not play a significant role with respect to failure. However, resource scarcity (H3a); symbolic information use (H4a); strategy championing (H5a); and, tenure (H6a) are shown to be significant drivers of strategy failure in high adherence organizations. For the low adherence group, symbolic information use, strategy championing, and tenure are not related to strategy failure but formalization (H2b) and resource scarcity (H3b) are positively related. In addition, centralization (H1b) exhibits a significant negative relationship 
with failure, and therefore can mitigate the possibility of failure occurring in low adherence organizations. It would appear, then, that strategy failure in high adherence organizations is mostly a consequence of managerial factors (notwithstanding resource scarcity), whereas low adherence organizations are subject to being more strongly affected by structural factors.

\section{Additional Analysis}

We sought to examine the managerial and structural conditions that can lead to strategy failure. But the long-term implication of this for the organization is that multiple strategy failures over a prolonged period of time will likely lead to organizational failure. To research this potential further, we gathered objective data on failure as represented by the Quiscore. This score is a form of credit rating and reflects the risk of absolute organizational failure—death—where low Quiscores indicate imminent danger of organizational failure. As additional analysis, we consider the effects of our independent variables on this risk of absolute failure. Introducing this Quiscore of failure into the restricted and unrestricted SEM models show once again that the unrestricted model is superior $\left(\Delta \chi^{2}\right.$ [d.f.] $=12.6$ [6]; $\left.p \leq .05\right)$. For the high adherence group, symbolic information use $(t=1.90 ; p \leq .05)$ and championing $(\mathrm{t}=-2.27 ; p \leq .05)$ are significant, indicating that whilst the misuse of information can bring down strategies it does not necessarily mean so for the company as a whole but championing again raises concerns. Results for the low adherence group indicate formalization $(\mathrm{t}=-1.28, p \leq .10)$ and symbolic information use $(\mathrm{t}=-1.28 ; p \leq .10)$ are significant causes of organizational failure and strategic managers must clearly be aware of these conditions when managing strategies given their effect on the survivability of their organizations. Whilst the results between strategy failure and absolute organizational failure, differ, it is apparent that variables that can cause strategies to fail can also lead to company failure and suggest a degree of robustness to our results. 


\section{Discussion and Implications}

As strategy failure often underlie, and are root causes of, organizational failure, we sought in this research study to examine the effect of structural and managerial factors on strategy failure to determine the extent to which these factors lead to strategy failure at high and low levels of adherence to the product-market strategy. In doing so, we contribute knowledge of conditions that exacerbate strategy failure in high and low adherence firms, and we demonstrate that both groups exhibit different antecedents to strategy failure. Our work is unusual in that we abandon the assumption that low adherence firms simply exhibit different levels of the same conditions as high adherence firms. In turn, our work offers much better understanding of how strategy failure arises in very different groups of organizations. Four contributions to the theory of adherence and its interrelationship with strategy failure result from our findings.

First, scholars often eschew opportunities to research strategy failures in favor of examining conditions for high performance. Consequently, the depth of knowledge on the drivers of strategy failure and its remedies are much less well known to strategic managers. We add to the body of literature on strategy failure and reveal important structural and managerial factors that drive strategy failure. Regardless of whether an organization strictly adheres to its strategy or adopts a more flexible approach, resource scarcity affects the capacity of firms to readily adapt and in both groups exacerbates strategy failure. But in terms of organizations that favor high adherence, the drivers of strategy failure are otherwise managerial, with symbolic information use, strategy championing and tenure all antecedents of strategy failure. In low adherence firms though, only the structural factors are antecedents to strategy failure, albeit centralization can mitigate and reduce the risk of failure as it exerts the opposite effect to our expectations. These insights contribute valuable knowledge to our understanding of failure in firms by demonstrating 
that the drivers of failure vary by the nature of a firm's strategic approach and does not follow the logic of a simple dichotomy. Accordingly, our contribution meets calls by Baumard and Starbuck (2005) among others for better understanding of strategy failure, the context of such failure, and its drivers.

Second, by breaking up the adherence dynamic present in firms, we can see how managerial and structural conditions exacerbate failure and impede management from readily diagnosing and implementing changes in strategy. Consequently, the findings suggest that strategic managers themselves are not solely to blame for strategy failure but that failure is a product of several intertwining conditions. Our findings then contribute to the literature on failure and caution us from readily apportioning blame to the behavior of strategic managers or resource weaknesses alone. Indeed, we contribute new findings to show how a blend of structural and managerial conditions can create strategy failure, thereby expanding considerably on findings by Khanna and Poulson (1995) that managers' decisions are not solely to blame for organizational distress. Thus, we conclude, organizations must thoroughly analyze why strategies failed and why performance is degrading and not be quick to simply blame specific strategic managers or poor trading conditions. There may well be important underlying structural issues at play.

Our contribution suggests that the effect of resource scarcity on strategy failure might mask managers from readily understanding the interplay of factors affecting strategy failure. In turn, we contribute to the strategic management debate on structural and managerial constituencies that affect firm performance, create the conditions that perpetuate decline, and the inhibiting factors that support strategy failure as opposed to preventing it (Mellahi and Wilkinson, 2004). In terms of adherence theory, we show that it is not managers' strict adherence to strategy or not that causes strategy failure, but rather the confluence of managerial and structural characteristics present in the firm. Although this is in part supportive of strategic fit 
theory, the concept of a firm-environment-strategy match belies the interaction among different constituents in the firm to shape strategy failure. Bringing strategic fit theory together within that of adherence shows that the recipe for failure is empirically different. Thus, we reconcile these two lines of argument and add new insight into the mechanisms responsible for strategy failure in low adherence and high adherence situations, moving the focus from the strategic manager alone to more broader issues. In turn, we address calls by Mellahi and Wilkinson (2004) among others to understand the context and organizational dynamics underpinning strategy failure.

Third, two important conditions that might generate strategy failure according to theory are resource scarcity and symbolic information use. Covin et al. (1997) suggested that resource scarcity would lead to a propensity to adhere to current strategy, and consequently such adherence would cause failure. There is also some literature to associate resource weaknesses with problems of poor performance and our findings build on this body of research. Indeed, in both adherence groups, resource scarcity was a driver of strategy failure. The literature on symbolic information use also frequently suggests it has negative connotations for performance but very seldom do such studies go on to demonstrate this concern empirically (Diamantopoulos and Souchon, 1999; Vyas and Souchon, 2003). We empirically show this assertion is correct for strategy failure under conditions of high adherence. When organizations are more flexible this is not the case, perhaps because such firms rely less on information due to cost, but when symbolic information use is present, it can cause absolute organizational failure in low adherence firms. We therefore contribute empirical evidence to support the concerns raised about resource scarcity and symbolic information use by strategy scholars, but in doing so we distil in richer detail their effects on the firm.

A final important contribution relates to strategy championing. The normative assumption present in management literature is that championing is a positive trait for organizations. 
However, Royer (2003) demonstrated that championing could have negative consequences at the project level. We quantitatively validate this concern at the strategic level. Championing is not inevitably beneficial and can lead to strategy failure in organizations that habitually persist with current strategies. Thus, we contribute new evidence that supports the growing discontent with championing as a ubiquitous high-performance trait. By linking championing to the theory of adherence, we show that championing can exacerbate the resistance to change that is symptomatic of strategy adherence. Thus, our contribution encourages greater reflection critical reflection on the positive and negative role championing can play in the strategy process.

\section{Implications for Managers}

Schendel et al. (1976) indicated that downturns were a result of unfavorable environmental shifts combined with inefficiency or inappropriate competitive strategies. We argued that strategy failure, as considerably substandard business performance relative to major, director competitor referents, over time and multiple strategy failures will lead to creating decline (be it rapid or otherwise) which ultimately leads to organizational failure (Hambrick and D’Aveni, 1992; Finkelstein, 2003). We suggest that strategy failure can be addressed by managers before it is too late and organizational failure occurs. As Whetten (1980) indicated: by the time decline is complete, firms are often in a state of strategic paralysis and unable to change strategy sufficiently to save them from organizational death. In order to address strategy failure however, one needs an understanding of what can cause/mitigate it.

It is apparent that high adherence organizations are likely to be more prone to failure on the basis that a greater number of conditions appear to drive strategy failure in these types of firms. Specifically, managerial characteristics have a significant influence on strategy failure along with resource scarcity. Structural concerns such as centralization and formalization should be of less concern to strategic managers when firms exhibit high adherence as these conditions 
bear no influence on failure therein. Despite the fact that resource scarcity is perennial a problem for managers, our findings show that managerial considerations are just as important if not more so given that strategic managers have the power to ensure that the managerial climate is not one that is conducive to failure. Strategic managers must guard against abusing information and developing product-market strategies on the back of poor and misused information in particular. To this end, we suggest a climate of learning and information sharing be developed so that all organizational members are clear on the need to be focused on learning by developing shared understanding throughout the organization of all information gathered and knowledge created. Trust and a unified belief in the good of the organization are likely to be key factors in stifling information misuse. These same factors should also encourage reflection and the reevaluation of strategies to better manage the consequences of high strategy adherence.

In low adherence firms, resource scarcity is again important but so are structural conditions. Managers must ensure the firm's structural dimensions create rather than impede a capacity for flexibility. Low adherence firms are more flexible than high adherence firms, in theory, and maintaining this flexibility requires a degree of informality and freedom for organizational members in undertaking their work. Still while formalization does indeed drive strategy failure in these types of firms, we also show that some centralization can help to mitigate the risk of failure. Strategic managers should be mindful of this dynamic to ensure that a suitable organizational framework is in place to not only limit adherence but to encourage organizational members to learn to improve working practices as a pathway to avoid strategy failure.

An overarching implication for both high and low adherence firms is the problem posed by resource scarcity. Caution must be taken against developing resource weaknesses (West and DeCastro, 2001), or overusing resources such that they become scarce in the organization, or allowing resources to diminish without sufficient investment in their renewal. Scarcity in the 
firm's resource base limits the ability of strategic managers to pursue new market opportunities and can blind strategic managers to orient their product-market strategies to avoid threats so as not to exacerbate the effects of resource limitations. Therein, resource scarcity becomes a key driver of failure. Managers must devote constant attention to the resource base of the firm so as to not let it diminish to the point that it creates a risk of strategy failure. Managers then should invest in a steady stream of resource acquisition initiatives, resource-based alliances, $R \& D$, and resource bundling projects to minimize the risk of creating creeping weaknesses in the resourcebase of the firm.

Championing has long been associated with new product success in the new product development literature; however, in recent years its role in strategy has been questioned. Royer (2003) examined two cases of organizations suffering from failure and noted how champions were a negative influence on change in these organizations. We demonstrate empirically in this study that strategy championing can indeed generate strategy failure. Product-market strategies can be over-adhered through championing to beyond the point at which they are appropriate or the point at which strategic fit is eroded and the strategy becomes damaging. Strong championing can inhibit strategic change. Strategic managers must be mindful that when championing strategies, they do not build a climate that is hostile to change or is complacent change. Managers must ensure a capacity for flexibility exists so that the product-market strategy can be rapidly adapted as and when is necessary.

Lastly, strategic managers can become entrenched in their views and experiences and this has been associated with poor performance and a lack of adaptation. We demonstrate that tenure has a significant effect on strategy failure in organizations characterized by high adherence. It is apparent that long-tenured strategic managers must be willing to forgo the past and learn to continuously improve in order to stay ahead of competitors, employing contemporary as opposed 
to past practices and strategic actions. Still, manager tenure does not appear to affect strategy failure in firms characterized by low adherence. Managers of low adherence firms appear to symbiotically share the same flexibility espoused by their firms. The appointment of strategic managers therefore seems a crucial component of the future adherence state of the organization, and the risk of strategy failure therein.

\section{Implications for Theory}

Adherence theory as advanced by several authors, most notably Lant et al. (1992), Covin et al. (1997), Fox-Wolfgramm et al. (1998), and Hughes and Morgan (2007) posits that managers and organizations typically persist or adhere to current strategies and strategic trajectories even in the face of environmental upheaval, rather than seek to make major strategic changes or change strategy to match/fit environmental conditions. Strategic fit theory clearly states that in circumstances of adherence to strategy, the strategy will likely fail because it does not best suit the environmental conditions in which the firm operates. To succeed, a new strategy should be developed to generate strategic fit. Proponents of adherence however contend that failure is not a given. In turbulent times, one clear strategy provides clarity of direction and makes use of what strategic resources and capabilities the organization has and as such is therefore the best strategy to continue with. If the environment is turbulent such that it is dynamic and continually changing then modifying strategy on a frequent basis creates uncertainty and flux which may disrupt the organization as well as hindering implementation efforts. Therefore, the current strategy should be adhered to (Covin et al., 1997).

Whilst there are merits to adherence (e.g., Hughes and Morgan, 2007) it is clear that situations arise where failure will occur due to it and change must occur before organizational failure occurs. This research enriches adherence theory with information on how adherence can become negative and why it occurs. We suggest that adherence theorists needs to recognize 
strategic fit theory and develop a comprehensive understanding of the conditions in which adherence is appropriate and inappropriate beyond simple examinations of turbulent/benign environments as is the tendency in both literature streams.

\section{Study Limitations and Opportunities for Future Research}

Several limitations affect this study. First, we rely on a cross-sectional design. From this we cannot infer whether the identified relationships hold over time and suggest a longitudinal study is a necessary next step. Second, we employ a single informant approach. Although no common method problems were found, scholars have indicated that data generated from a multiple informant approach is preferred. Whilst generating data from a single informant is valid we do acknowledge this as a limitation of our work. This issue is mitigated by the use of objective data in the additional analyses which do bear some consistency with the original results and indicate that the use of subjective single-source data was robust. Third, gaining access into actual failing organizations is difficult as they are more inclined to focus on addressing their problems and implementing turnaround strategies than to admit serious problems and take part in surveys. We found this to be a significant issue in developing our sample and so relied on reverse coded items to assess strategy failure. Although we supplement our work with objective measures of the risk of absolute organizational failure, identifying and measuring failure in firms remains a difficult challenge for scholars. Fourth, we sampled high-technology organizations from the UK and caution against generalizing our results into industry contexts significantly beyond those described here. We appreciate that our research design choice in this respect does impose some limitations on the generalizability of our findings, but we feel that our multi-industry sample of high-technology firms is relevant and the findings are relevant to this important audience. Nonetheless, it would be useful to see data from other non-technology based industries (although such sample heterogeneity carries its own problems). Beyond this, future research could extend to 
examine strategy failure in industries that are stable relative to unstable industries. Initial work by Covin et al (1997) in this area found that environmental hostility moderated the adherenceperformance relationship and adherence was positive in hostile situations. This work contradicts much of the planning literature however that tends to find that steadfast planning in turbulent environments damages performance. This would then indicate the need for further research. Fifth, we do not discuss young and small firms in our work. Recent literature on learning advantages of newness suggests that young firms may be able to defend against managerial and structural problems in meeting new opportunities owing to their lack of formal structure and lack of historical knowledge to bias organizational action (Sapienza et al., 2006). Nonetheless, age can undermine survival and lead to premature failure (Sapienza et al., 2006) and so our methodological choices are appropriate. But the study of failure in young firms is largely stagnant and over-reliant on age-related theories such as liabilities of newness. Thus, whilst our findings do not pertain to this class of firms, we do believe this is an interesting opportunity for future research. Sixth, our sample is limited to high-technology firms. While this is appropriate given the risks these firms face from regular environmental and market change, we cannot generalize to other more stable contexts and it would be useful to explore our framework in other industries. Taken together, these limitations signal possible avenues for future research.

Several further opportunities for future research arise from this study. The role of championing requires immediate research. It is commonly taken for granted in the new product development and marketing literatures that championing has positive benefits with little negative implications. Our results confirm Royer's (2003) assertions regarding the negative power of championing and call for further research to examine the conditions in which product-market strategy championing may prove negative to organizations. Understanding the context in which championing occurs and the situations that mitigate it from having harmful effects through 
maintaining the strategic status quo will be beneficial to researchers and managers alike. Building on this, it may be that a market orientation or a climate for learning may moderate the relationship between championing and failure. By being market aware and willing to learn generatively as time passes, champions may develop a heightened awareness for market changes in customer needs, value, and competitor actions. As such, they may well then understand and champion the cause of strategy change as opposed to strategy adherence. Still, further research is certainly needed into this relationship as the results of Royer's (2003) study suggested that such deviance may not occur due to the blindness caused by excessive championing.

More research is needed into strategy failure in flexible, low adherence firms. We recognize that there are many more structural and managerial characteristics that could be considered beyond those examined here. We suggest particular focus is given to flexible organizations, their mechanisms for learning, capability to adapt, and the conditions under which flexibility may be constrained such that failure could set in.

Despite recent studies, the body of literature on strategy failure is fragmented and in its infancy. Much more research is needed into the causes of strategy failure and how to remedy the situation before total failure becomes inevitable. We suggest that this is a crucial avenue for scholars to pursue. Further, given our problems in surveying failing companies a focus on a limited number of organizations through qualitative work may be useful to supplement widespread sampling. For the time being however, we feel our approach to modeling strategy failure is theoretically consistent and a prudent approach to breaching this important area of research. As the literature on strategy failure increases then opportunities to develop and test a broader model of strategy failure will become an important research issue. 


\section{References}

Armstrong, J.S., and Overton, T.S. (1977). Estimating non-response bias in mail surveys. Journal of Marketing Research, 14, 396-403.

Atuahene-Gima, K., and Murray, J.Y. (2004). Antecedents and outcomes of marketing strategy comprehensiveness. Journal of Marketing, 68, 33-46.

Barker III, V.L., and Duhaime, I.M. (1997). Strategic change in the turnaround process: Theory and empirical evidence. Strategic Management Journal, 18, 13-38

Baumard, P. and Starbuck, W.H. (2005). Learning from failures: Why it may not happen. Long Range Planning, 38, 281-298.

Biyalogorsky, E., Boulding, W., and Staelin, R. (2006). Stuck in the past: Why managers persist with new product failures. Journal of Marketing, 70 (April), 108-121.

Bollen, K.A. (1989). Structural Equations with Latent Variables. New York, NY: Wiley. Covin, J.G., Slevin D.P., and Schultz, R.L. (1997). Top management decision sharing and adherence to plans. Journal of Business Research, 40, 21-36.

D’Aveni, R.A. (1989). The aftermath of organizational decline: A longitudinal study of the strategic and managerial characteristics of declining firms. Academy of Management Journal, 32, 577-605.

Diamantopoulos, A., and Souchon, A.L. (1999). Measuring export information use: Scale development and validation. Journal of Business Research, 46, 1-14.

Finkelstein, S. (2003). Why Smart Executives Fail and What you can Learn from their Mistakes. New York, NY: Portfolio. 
Finkelstein, S., and Hambrick, D.C. (1990), Top-management-team tenure and organizational outcomes: The moderating role of managerial discretion. Administrative Science Quarterly, 35, 484-503.

Fox-Wolfgramm, S.J., Boal, K.B., and Hunt, J.G. (1998). Organizational adaptation to institutional change: A comparative study of first-order change in prospector and defender banks. Administrative Science Quarterly, 43, 87-126.

Grewal, R., and Tansuhaj, P. (2001). Building organizational capabilities for managing economic crises: The role of market orientation and strategic flexibility. Journal of Marketing, 65 (April), 67-80.

Hambrick, D.C., and D’Aveni, R.A. (1988). Large corporate failures as downward spirals. Administrative Science Quarterly, 33, 1-23.

Hambrick, D.C., and D’Aveni, R.A. (1992). Top team deterioration as part of the downward spiral of large corporate bankruptcies. Management Science, 38, 1445-1466.

Hambrick, D.C., and Fukutomi, G.D.S. (1991). The seasons of a CEO's tenure. Academy of Management Review, 16, 719-742.

Hambrick, D.C., Geletkanycz, M.A., and Fredrickson, J.W. (1993). Top executive commitment to the status quo: Some tests of its determinants. Strategic Management Journal, 14, 401-418. Henderson, A.D., Miller, D. and Hambrick, D.C. (2006). How quickly do CEOs become obsolete? Industry dynamism, CEO tenure, and company performance. Strategic Management Journal, 27, 447-460.

Howell, J.M., and Shea, C.M. (2001). Individual differences, environmental scanning, innovation framing, and champion behavior: Key predictors of project performance. Journal of Product Innovation Management, 18, 15-27. 
Howell, J.M., and Shea, C.M. (2006). Effects of champion behavior, team potency, and external communication activities on predicting team performance. Group \& Organization Management, $31,180-211$.

Hu, L., and Bentler, P.M. (1999). Cutoff criteria for fit indices in covariance structure analysis: conventional criteria versus new alternatives. Structural Equation Modeling, 6, 1-55.

Hughes, P., and Morgan, R.E. (2007). A resource-advantage perspective of product-market strategy performance \& strategic capital in high technology firms. Industrial Marketing Management, 36, 503-517.

Jöreskog, K.G and Sörbom, D. (1996). LISREL8: User's reference guide. Chicago, IL: Scientific Software International.

Khanna, N., and Poulsen, A.B. (1995). Managers of financially distressed organizations: Villains or scapegoats? Journal of Finance, 50, 919-940.

Lant, T.K., Milliken, F.J., and Batra, B. (1992). The role of managerial learning and interpretation in strategic persistence and reorientation: An empirical exploration. Strategic Management Journal, 13, 585-608.

Miller, D. (1991). Stale in the saddle: CEO tenure and the match between organization and environment. Management Science, 37, 34-52.

Miller, D., and Shamsie, J. (2001). Learning across the life cycle: Experimentation and performance among the Hollywood studio heads. Strategic Management Journal, 22, 725-745. Mellahi, K. (2005). The dynamics of boards of directors in failing organizations. Long Range Planning, 38, 261-279.

Mellahi, K., and Wilkinson, A. (2004). Organizational failure: A critique of recent research and a proposed integrative framework. International Journal of Management Reviews, 5/6, 21-41. 
Menon, A., and Varadarajan, P.R. (1992). A Model of marketing knowledge use within firms. Journal of Marketing, 56 (October), 53-71.

Menon, A., Bharadwaj, S.G., Adidam, P.T., and Edison, S.W. (1999). Antecedents and consequences of marketing strategy making: A model and a test. Journal of Marketing, 63 (April), 18-40.

Morgan, N.A., Vorhies, D.W., and Mason, C.H. (2009). Market orientation, marketing capabilities, and firm performance. Strategic Management Journal, 30, 909-920.

Morgan, R.E., and Strong, C.A. (2003). Business performance and dimensions of strategic orientation. Journal of Business Research, 56, 163-176.

Noble, C.H., and Mokwa, M.P. (1999). Implementing marketing strategies: Developing and testing a managerial theory. Journal of Marketing, 63 (October), 57-73.

Podsakoff, P.M., MacKenzie, S.B., Lee, J.-Y., and Podsakoff, N.P. (2003). Common method biases in behavioral research: A critical review of the literature and recommended remedies. Journal of Applied Psychology, 88, 879-903.

Powell, T.C. (1992). Strategic planning as competitive advantage. Strategic Management Journal, 13, 551-558.

Royer, I. (2003). Why bad projects are so hard to kill. Harvard Business Review, 81 (February), 48-56.

Sapienza, H.J., Autio, E., George, G., and Zahra, S.A. (2006). A capabilities perspective on the effects of early internationalization on firm survival and growth. Academy of Management Review, 31 (4), 914-933.

Schendel, D.G., Patton, R., and Riggs, J. (1976). Corporate turnaround strategies: A study of profit decline and recovery. Journal of General Management, 3, 3-11. 
Sheppard, J.P., and Chowdhury, S.D. (2005). Riding the wrong wave: Organizational failure as a failed turnaround. Long Range Planning, 38, 239-260.

Slevin, D.P., and Covin, J.G. (1997). Strategy formation patterns, performance and the significance of context. Journal of Management, 23, 189-209.

Stinchcombe, A L. (1965). Social structure and organizations. In J.G. March (Ed.), Handbook of Organizations (142-193). Chicago, IL: Rand McNally.

Sull, D., (1999). Why good companies go bad. Harvard Business Review, 77, 42-51. Varadarajan, P.R., and Jayachandran, S. (1999). Marketing strategy: An assessment of the state of the field and outlook. Journal of the Academy of Marketing Science, 27, 120-143.

Vorhies, D.W., and Morgan, N.A. (2003). A configuration theory assessment of organization fit with business strategy and its relationship with marketing performance. Journal of Marketing, 67 (January), 100-115.

Vyas, R., and Souchon, A.L. (2003). Symbolic use of export information: A multidisciplinary approach to conceptual development and key consequences. International Marketing Review, 20 (1), 67-94.

West, G.P., and DeCastro, J. (2001). The Achilles heel of firm strategy: Resource weaknesses and distinctive inadequacies. Journal of Management Studies, 38, 417-442.

Whetten, D.A. (1980). Sources, responses and effects of organizational decline. In J.R. Kimberly, R. H. Miles, \& Associates (Eds.), The Organizational Life Cycle: Issues in the Creation, Transformation and Decline of Organizations (342-374). Washington: Jossey-Bass.

Zajac, E.J., Kraatz, M.S., and Bresser, R.K.F. (2000). Modeling the dynamics of fit: A normative approach to strategic change. Strategic Management Journal, 21, 429-453. 
Table 1

Measurement Item Properties

\begin{tabular}{|c|c|c|}
\hline Construct & $\begin{array}{c}\text { Standardized } \\
\text { Factor } \\
\text { Loading }\end{array}$ & $t$-value \\
\hline \multicolumn{3}{|l|}{ Centralization } \\
\hline There can be little action taken in the organization until a superior makes a decision & .82 & $-^{\mathrm{a}}$ \\
\hline $\begin{array}{l}\text { A person who wants to make his or her own decisions would be quickly discouraged in the } \\
\text { organization }\end{array}$ & .73 & 9.18 \\
\hline Even small matters have to be referred to someone with more authority for a final decision & .84 & 11.03 \\
\hline Any decision a person in the organization makes has to have his or her boss's approval & .82 & 10.73 \\
\hline \multicolumn{3}{|l|}{ Formalization } \\
\hline Most people in the organization follow written work rules for their job & .49 & $-^{\mathrm{a}}$ \\
\hline How things are done in the organization is never left up to the person doing the work & .79 & 4.09 \\
\hline \multicolumn{3}{|l|}{ Resource Scarcity } \\
\hline $\begin{array}{l}\text { The right kinds of resources are allocated to the implementation efforts for this product- } \\
\text { market strategy }\end{array}$ & .80 & $-^{\mathrm{a}}$ \\
\hline $\begin{array}{l}\text { Adequate resources are allocated to the implementation efforts for this product-market } \\
\text { strategy }\end{array}$ & .92 & 12.23 \\
\hline The resource structure is now well aligned with the product-market strategy requirements & .87 & 11.57 \\
\hline \multicolumn{3}{|l|}{ Symbolic information use } \\
\hline $\begin{array}{l}\text { Information is often collected to justify a strategic product-market decision already made } \\
\text { Information is used to justify strategic product-market decisions is often }\end{array}$ & .80 & $-^{\mathrm{a}}$ \\
\hline collected/interpreted after the decision has been made & .72 & 7.72 \\
\hline Information is often used to reinforce expectations & .76 & 7.96 \\
\hline \multicolumn{3}{|l|}{ Strategy Championing } \\
\hline I felt that this product-market strategy lacked a true leader in the organization (r) & .48 & $-^{\mathrm{a}}$ \\
\hline $\begin{array}{l}\text { One person in the organization definitely took charge of making this product-market } \\
\text { strategy happen }\end{array}$ & .64 & 4.97 \\
\hline $\begin{array}{l}\text { The product-market strategy had a 'champion' to guide it through the implementation } \\
\text { process }\end{array}$ & .92 & 5.11 \\
\hline \multicolumn{3}{|l|}{ Tenure } \\
\hline Tenure with current organization & .84 & 11.75 \\
\hline \multicolumn{3}{|l|}{ Adherence } \\
\hline My organization almost always adheres closely to its intended product-market strategy & .70 & $-^{\mathrm{a}}$ \\
\hline Modifications to my organization's intended product-market strategy are typically minimal & .46 & 4.79 \\
\hline In general, my organization is very effective at implementing chosen strategies & .79 & 7.58 \\
\hline $\begin{array}{l}\text { My organization is almost always able to implement the strategies it would most like to } \\
\text { employ }\end{array}$ & .72 & 7.21 \\
\hline \multicolumn{3}{|l|}{ Strategy Failure } \\
\hline Sales growth & .71 & $-{ }^{\mathrm{a}}$ \\
\hline Return on investment & .80 & 8.80 \\
\hline Profitability & .84 & 9.24 \\
\hline 'Overall' firm performance & .90 & 9.70 \\
\hline
\end{tabular}

${ }^{\mathrm{a}}$ Item fixed to set the scale.

(r) Item reverse-coded for analysis purposes. 
Table 2

Construct Robustness and Descriptive Statistics

\begin{tabular}{lcccccccccc}
\hline & CR & AVE & X1. & X2. & X3. & X4. & X5. & X6. & X7. & X8. \\
\hline X1. Centralization & .88 & .65 & $.81^{\mathrm{a}}$ & & & & & & & \\
X2. Formalization & .59 & .43 & $.46^{* *}$ & .66 & & & & & \\
X3. Resource scarcity & .90 & .74 & $.36^{* *}$ & .13 & .86 & & & & \\
X4. Symbolic information use & .81 & .58 & .09 & .08 & -.01 & .76 & & & \\
X5. Strategy championing & .73 & .49 & $-.35^{* *}$ & $-.29^{* *}$ & $-.52^{* *}$ & -.11 & .70 & & & \\
X6. Tenure & n/a & n/a & -.05 & -.03 & -.07 & .03 & .05 & n/a & & \\
X7. Adherence & .77 & .46 & -.13 & -.13 & $-.34^{* *}$ & $-.38^{* *}$ & $.31^{* *}$ & -.06 & .68 & \\
X8. Strategy failure & .89 & .66 & .11 & .06 & $.28^{* *}$ & .12 & -.11 & .12 & -.10 & .81 \\
& & & & & & & & & & \\
Mean & & & 3.13 & 2.75 & 3.76 & 4.05 & 4.78 & 10.59 & 4.54 & 3.02 \\
SD & & & 1.32 & 1.21 & 1.30 & 1.20 & 1.16 & 8.99 & 1.04 & 1.05 \\
\hline$* * p<.01$
\end{tabular}

CR: Composite reliability.

AVE: Average variance extracted.

SD: Standard deviation.

${ }^{a}$ Figures on the diagonal are square roots of AVE.

$\mathrm{n} / \mathrm{a}$ : Not applicable (single measure latent variable). 
Table 3

Multi-group SEM Results for High and Low Adherence Organizations

\begin{tabular}{|c|c|c|c|c|c|}
\hline & $\begin{array}{l}\text { Independent } \\
\text { variable }\end{array}$ & & $\begin{array}{c}\text { Dependent } \\
\text { variable } \\
\end{array}$ & $\begin{array}{l}\text { Standardized } \\
\text { path estimate }\end{array}$ & $t$-value ${ }^{a}$ \\
\hline \multicolumn{6}{|c|}{ High Adherence Organizations } \\
\hline Hypothesis 1a. & Centralization & $\rightarrow$ & Strategy failure & -.12 & -.67 \\
\hline Hypothesis 2a. & Formalization & $\rightarrow$ & Strategy failure & .04 & .22 \\
\hline Hypothesis 3a. & Resource scarcity & $\rightarrow$ & Strategy failure & .53 & $3.49 * *$ \\
\hline Hypothesis 4a. & Symbolic information use & $\rightarrow$ & Strategy failure & .22 & $1.99 *$ \\
\hline Hypothesis $5 a$. & Strategy championing & $\rightarrow$ & Strategy failure & .37 & $2.31^{*}$ \\
\hline Hypothesis 6a. & Tenure & $\rightarrow$ & Strategy failure & .15 & $1.39^{\dagger}$ \\
\hline \multicolumn{6}{|c|}{ Low Adherence Organizations } \\
\hline Hypothesis $1 \mathrm{~b}$. & Centralization & $\rightarrow$ & Strategy failure & -.53 & $-1.76^{*}$ \\
\hline Hypothesis $2 \mathbf{b}$. & Formalization & $\rightarrow$ & Strategy failure & 1.02 & $2.77^{* *}$ \\
\hline Hypothesis $3 \mathbf{b}$. & Resource scarcity & $\rightarrow$ & Strategy failure & .44 & $1.85^{*}$ \\
\hline Hypothesis $\mathbf{4 b .}$ & Symbolic information use & $\rightarrow$ & Strategy failure & .24 & 1.27 \\
\hline Hypothesis $5 b$. & Strategy championing & $\rightarrow$ & Strategy failure & .14 & .56 \\
\hline Hypothesis 6b. & Tenure & $\rightarrow$ & Strategy failure & .20 & 1.05 \\
\hline
\end{tabular}


Figure 1

A Model of Strategy Failure

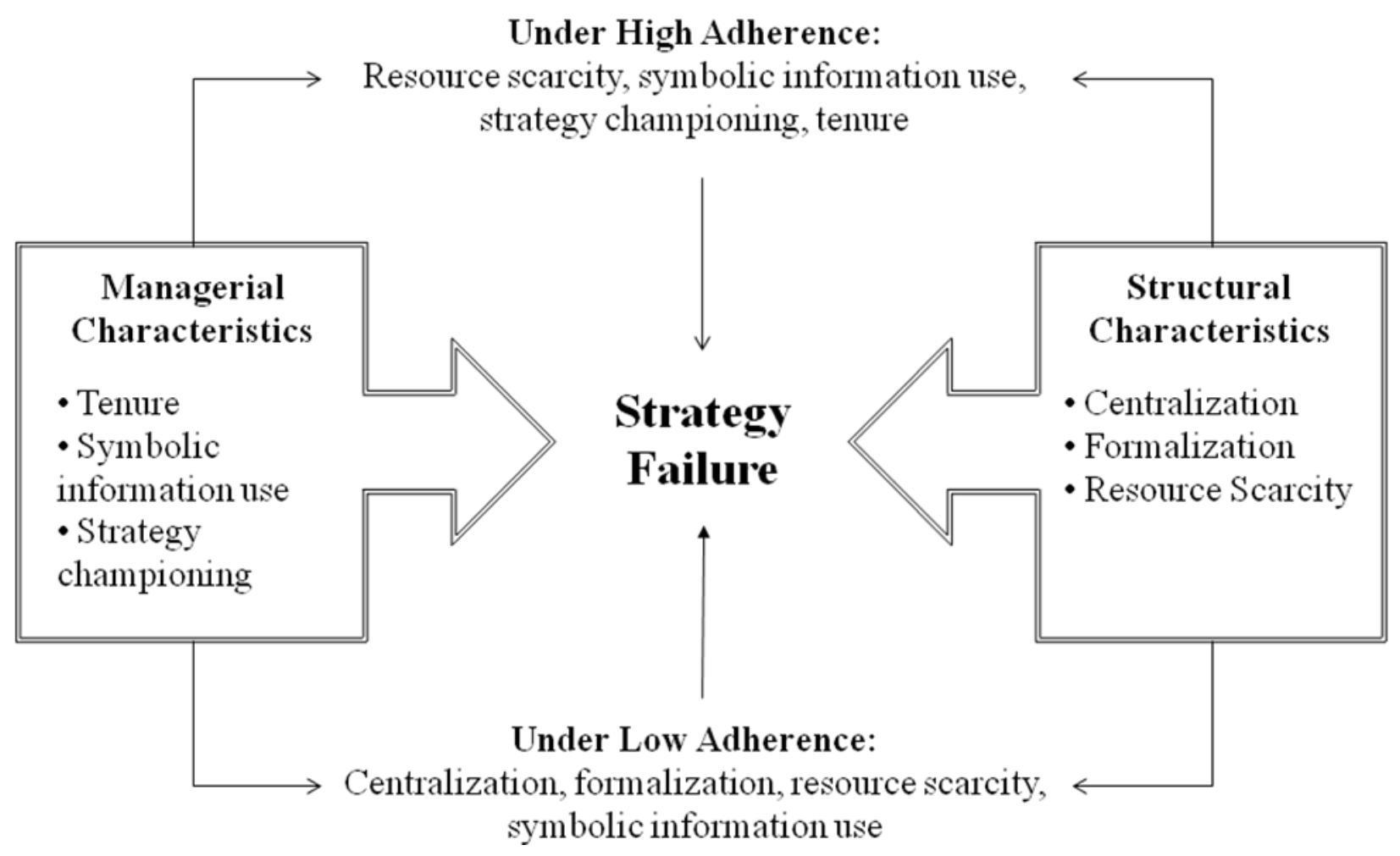

